\title{
HUBUNGAN PENGETAHUAN DAN STATUS GIZI IBU HAMIL TERHADAP RISIKO ANEMIA IBU HAMIL DI PUSKESMAS KERENG BANGKIRAI
}

\author{
Oktaviani $^{1}$, Lola Meyasa ${ }^{2}$ \\ ${ }^{1,2}$ Program Studi DIII Kebidanan, Poltekkes Kemenkes Palangka Raya, Kalimantan Tengah \\ Email:Oktaviani@poltekkes-palangkaraya.ac.id
}

\begin{abstract}
ABSTRAK
Anemia pada kehamilan memerlukan perhatian karena potensial membahayakan ibu dan anak. Anemia pada ibu hamil meningkatkan risiko kematian ibu. Tingginya kejadian anemia berkaitan dengan rendahnya pengetahuan menyebabkan rendahnya informasi yang diterima dan status gizi ibu hamil. Puskesmas Kereng Bangkirai merupakan salah satu puskesmas Pelayanan Obstetri Neonatal Emergensi Dasar (PONED) di Kota Palangka Raya dan jumlah ibu hamilnya mendapatkan tablet FE paling rendah. Tujuan penelitian untuk menganalisis hubungan pengetahuan dan status gizi terhadap risiko anemia pada ibu hamil di Puskesmas Kereng Bangkirai. Jenis penelitian ini dengan rancangan cross sectional. Populasi penelitian ini adalah seluruh lbu yang hamil yang ada di wilayah kerja Puskesmas Kereng Bangkirai periode 1 Januari sampai dengan 31 Desember 2015 berjumlah 226 orang. Sampel penelitian ini adalah lbu yang hamil yang ada di wilayah kerja Puskesmas Kereng Bangkirai berjumlah 140 responden. Pemilihan sampel dipilih dengan menggunakan consecutive sampling Analisis univariat dilakukan dengan distribusi frekuensi, analisis bivariat dengan chi-square.Hasil penelitian menunjukkan Variabel pengetahuan ibu ada hubungan bermakna dengan anemia $(p=0,04)$. Variabel status gizi ibu hamil tidak ada hubungan bermakna dengan anemia pada kehamilan. Kesimpulan:pengetahuan ibu merupakan faktor risiko kejadian anemia pada ibu hamil.
\end{abstract}

Kata kunci: Anemia dalam kehamilan, Pengetahuan Ibu hamil

\begin{abstract}
Anaemia during pregnancy requires attention due to potentially harm mother and infant. Furthermore, it is increased mother's risk to dead. It is suggested that the high rate on anaemia is related to level of knowledge and mothers' nutrition. The Kereng Bangkirai Health centre is one of the basic emergency on neonatal obstetric service, so-called PONED, in Palangka Raya. It is also notice that pregnant women having lowest number on Fe intake. This research was aimed to analyse the relationship between level of knowledge and nutrition status on maternity risk in Kereng Bangkirai Health Centre. Research was conducted using cross sectional design. Population was all pregnant women within Kereng Bangkirai health centre, on which recorded during January, 1st to Dec, 31st 2015 period. Calculated sample was 140 persons, using consecutive sampling technique. Univariate conducted through frequency distribution while bivariate analysis with chi-square. The study indicate that the mothers' level of knowledge having significant relationship with anaemia
\end{abstract}


$(p=0.04)$. Meanwhile, their nutrition status showed no linkage with anaemia. It is concluded that the mothers' cognition is risk factor to anaemia during pregnancy.

Keyword: anemia in pregnancy, pregnant women knowledge

\section{PENDAHULUAN}

Salah satu indikator untuk menilai derajat kesehatan perempuan adalah angka kematian ibu (AKI). Kematian ibu di Indonesia sebesar 30,3\% disebabkan karena perdarahan postpartum (Kemenkes, 2015). Diperkirakan jika pada tahun 2012-2015 prevalensi anemia masih tetap diatas $40 \%$, maka akan terjadi kematian ibu sebanyak 18 ribu per tahun yang disebabkan perdarahan setelah melahirkan. Kondisi ini akan menyebabkan 3-7 \% ibu meninggal karena penyebab tak langsung yaitu anemia [1]

Anemia merupakan suatu keadaan dimana tubuh memiliki jumlah sel darah merah (eritrosit) yang terlalu sedikit, yang mana sel darah merah itu mengandung hemoglobin yang berfungsi untuk membawa oksigen keseluruh jaringan tubuh.Pada masa kehamilan terjadi peningkatan kebutuhan zat besi tiga kali lipat untuk kebutuhan ibu hamil dan pertumbuhan janin [2].

Ibu hamil yang mengalami anemia akan berdampak baik pada masa kehamilan, persalinan dan nifas. Anemia pada masa kehamilan dapat menyebabkan keguguran, melahirkan sebelum waktunya, bayi lahir dengan berat tidak normal, perdarahan sebelum serta pada waktu melahirkan dan pada anemia berat dapat menimbulkan kematian ibu dan bayi. Pada janin dapat mengalami gangguan pertumbuhan, tidak mencapai tinggi yang optimal dan anak menjadi kurang cerdas. Anemia pada ibu hamil juga meningkatkan risiko kematian ibu.

Hasil penelitian Fajrin A,dkk (2012) melaporkan tingginya kejadian anemia berkaitan dengan kurangnya gizi pada ibu hamil, kurangnya asupan zat besi, mal absorbsi yang rendah. Selain itu, rendahnya pendidikan, informasi dan pengetahuan menyebabkan rendahnya informasi yang diterima. Penelitian Maskey M, Jha N, Poudel SI, Yadav D (2014) juga melaporkan bahwa pengetahuan lbu yang kurang berhubungan dengan anemia pada lbu hamil.

Dinas Kesehatan Kota Palangka Raya (2015), melaporkan jumlah kematian ibu yang dilaporkan pada tahun 2013 adalah sebesar 3 kasus dan pada tahun 2014 terjadi kenaikan yaitu sebesar 4 kasus yang dilaporkan, dengan penyebab kematian ibu adalah akibat eklamsia dan syok hipovolemik akibat perdarahan. Berdasarkan profil Dinas Kesehatan Kota Palangka Raya, jumlah ibu hamil yang paling sedikit mendapatkan tablet FE 1 dan FE 3 adalah Puskesmas Kerang 
Bangkirai sebesar 124 (44,93\%) dan 160 (57,97\%). Puskesmas Kereng Bangkirai merupakan salah satu puskesmas Pelayanan Obstetri Neonatal Emergensi Dasar (PONED) yang ada di Kota Palangka Raya. Puskesmas ini melayani pemeriksaan kehamilan, pertolongan persalinan dan pelayanan kesehatan ibu anak lain serta pelayanan keluarga berencana. Maka, berdasarkan latar belakang di atas peneliti tertarik melakukan penelitian ini.

Penelitian bertujuan untuk menganalisis hubungan pengetahuan dan status gizi terhadap risiko anemia pada ibu hamil di Puskesmas Kereng Bangkirai. Manfaat penelitian ini dapat menjadi informasi dan bahan masukan untuk meningkatkan pelayanan kesehatan dalam upaya pencegahan kejadian anemia pada ibu hamil

\section{METODOLOGI}

Rancangan penelitian ini adalah penelitian observasional analitik dengan rancangan cross sectional. Populasi penelitian ini adalah seluruh lbu yang hamil yang ada di wilayah kerja Puskesmas Kereng Bangkirai periode 1 Januari sampai dengan 31 Desember
2015 berjumlah 226 orang. Sampel pada penelitian ini ibu hamil yang berjumlah140 orang dihitung menggunakan rumus sampel penelitian deskriptif dengan populasi kecil. Pemilihan sampel dipilih dengan menggunakan consecutive sampling setiap pasien yang memenuhi criteria inklusi dan eklusi dijadikan sampel..

Teknik pengumpulan data dengan cara melakukan wawancara menggunakan kuesioner terpimpin dengan responden yang memenuhi kriteria inklusi dan eksklusi yan telah ditentukan oleh peneliti dan melakukan pemeriksaan HB dengan stik easy touch. Analisa data ujistatistik yang digunakan adalah chi-square test, karena variabel yang diuji bersifat kategori.Hasil yang diperolehadalahnilai $x 2, p$ value.

\section{HASIL DAN PEMBAHASAN \\ HASIL PENELITIAN}

\section{Karakteristik responden}

Karakteristik responden berdasarkan hasil penelitian pada ibu hamil yang memenuhi kriteria inklusi dan eksklusi ditunjukkan pada Tabel 1. sebagai berikut:

Tabel1.DistribusiKarakteristikResponden $(n=140)$

\begin{tabular}{lcc}
\hline \multicolumn{1}{c}{ Variabel } & $\mathbf{n}$ & Persentase (\%) \\
\hline Anemia & 51 & \\
$\quad$ Ya & 89 & 66,4 \\
$\quad$ Tidak & & 63,6 \\
Usialbu & 14 & 10 \\
$\quad$ 20 Tahun & 112 & 80 \\
20-35 Tahun & 14 & 10 \\
$\quad$ >35 Tahun & &
\end{tabular}




\begin{tabular}{lcc} 
Kurang & 83 & 59,3 \\
Cukup & 29 & 20,7 \\
Baik & 28 & 20 \\
Status Gizi & & \\
Lila <23,5 & 5 & 3,6 \\
Lila $\geq 23,5$ & 135 & 96,4 \\
\hline
\end{tabular}

Sumber: Data Primer

Berdasarkan Tabel1. Menunjukkan hasil penelitian bahwa lbu hamil di wilayah kerja Puskesmas Kereng Bangkirai yang mengalami Anemia sebesar 36,4\%. Ibu hamil paling banyak mengalami anemia ringan sebesar $32,1 \%$. Adapun klasifikasi anemia dapat dilihat pada Gambar1.

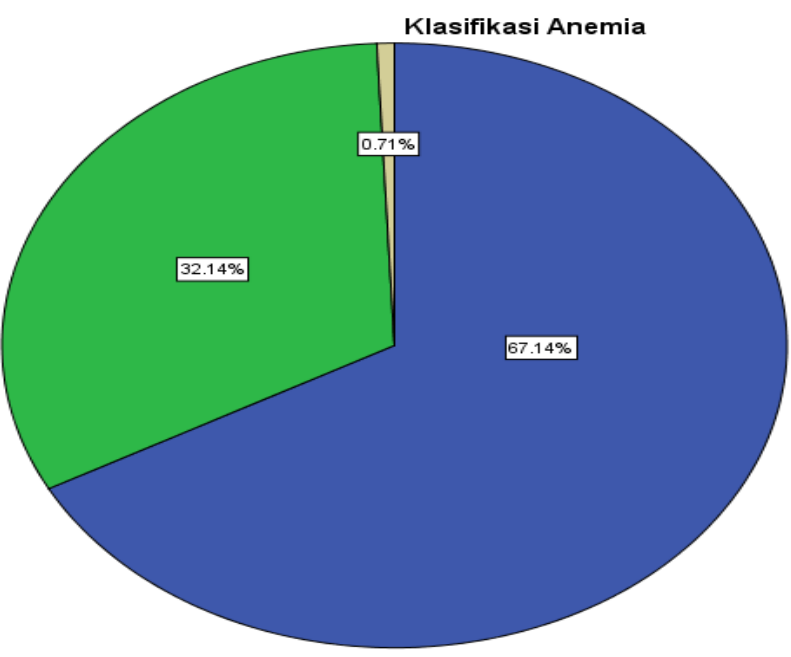
员idak Anemia
Anemia Ringan
Anemia berat

Gambar1.Klasifikasi Anemia

Pada Tabel 1. Hasil penelitian menunjukkan bahwa, usia lbu hamil paling banyak pad ausia 20-35 tahun (80\%). Untuk menilai status gizi bumil melalui pengukuran Lila, hasil penelitian menunjukkan bahwa paling banyak Lila Ibu hamil $\geq 23,5$ (96,4\%).Pada variable pengetahuan lbu, hasil penelitian menunjukkan bahwa pengetahuan Ibu hamil paling banyak memiliki pengetahuan kurang $(59,3 \%)$.
Hubungan Pengetahuan lbu dengan Kejadian Anemia

Pada variabel pengetahuan Ibu, hasil uji chi square menunjukkan ada hubungan bermakna dengan kejadian anemia $(p=0,66)$. Ibu hamil yang mengalami anemia paling banyak memiliki pengetahuan kurang sebesar $83 \%$. Nilai OR $2,9 \quad(95 \% \quad \mathrm{Cl} \quad 1,1-8,0) \quad$ artinya responden yang memiliki pengetahuan rendah cenderung 2,9 kali lebih berisiko mengalami anemia dibandingkan lbu 
hamil yang memiliki pengetahuan baik

(Tabel 2).

Tabel2.HubunganPengetahuanlbudengankejadian anemia( $n=140)$

\begin{tabular}{lcccccc}
\hline \multirow{2}{*}{ Variabel } & \multicolumn{2}{c}{ Anemia } & \multicolumn{2}{c}{ Tidak Anemia } & \multirow{2}{*}{$\chi^{2}$} & \multirow{2}{*}{$\mathrm{P}$} \\
\cline { 2 - 5 } & $\mathrm{n}$ & $\%$ & $\mathrm{n}$ & $\%$ & & \\
\cline { 1 - 5 } Pengetahuanlbu & 6 & 10,2 & 22 & 17,8 & & $0,04^{*}$ \\
$\quad$ Baik & 8 & 10,6 & 21 & 18,4 & & \\
Cukup & 37 & 30,2 & 46 & 52,8 & & \\
$\quad$ Kurang & &
\end{tabular}

Keterangan: nilai $p$ dihitung dengan uji chi square

Hubungan Status GizidenganKejadian Anemia

Berdasarkan hasil penelitian, pada variabel status gizi dengan menggunakan fisher's exact, menunjukkan bahwa tidak ada hubungan bermakna dengan kejadian anemia $(p=1,00)$. Pada ibu hamil dengan anemia paling banyak LILA $\geq 23,5$. Hasil analisis ditunjukkan pada Tabel 3 . Dibawah ini:

Tabel3.Hubungan Status Gizidengankejadian anemia( $n=140)$

\begin{tabular}{|c|c|c|c|c|c|c|}
\hline \multirow{2}{*}{ Variabel } & \multicolumn{2}{|c|}{ Anemia } & \multicolumn{2}{|c|}{ Tidak Anemia } & \multirow[b]{2}{*}{$\chi^{2}$} & \multirow[t]{2}{*}{$\mathrm{P}$} \\
\hline & $\mathrm{n}$ & $\%$ & $\mathrm{n}$ & $\%$ & & \\
\hline Status Gizi & & & & & 0,029 & 1,00 \\
\hline$<23,5$ & 2 & 1,8 & 3 & 3,2 & & \\
\hline$\geq 23,5$ & 49 & 49,2 & 86 & 85,8 & & \\
\hline
\end{tabular}

\section{PEMBAHASAN}

Pengetahuan ibu dengan anemia ibu hamil

Pada variable pengetahuan lbu, menunjukkan bahwa ada hubungan bermakna dengan kejadian anemia .Hasil penelitian ini, juga menemukan bahwa lbu yang memiliki pengetahuan rendah lebih berisiko mengalami anemia 2,9 kali dibandingkan lbu yang memiliki pengetahuan baik. Penelitian ini menunjukkan bahwa pengetahuan lbu hamil merupakan faktor risiko kejadian anemia pada Ibu hamil.

Hasil peneltian ini sama dengan hasil penelitian Maskey M, Jha N, Poudel SI, Yadav D (2014) juga melaporkan bahwa pengetahuan lbu yang kurang berhubungan dengan anemia pada lbu hamil $(p=0.01)$. Penelitian yang dilakukan oleh Jiji Darling B dan Rajagopal K (2014) juga melaporkan bahwa terdapat hubungan bermakna pengetahuan lbu dengan jenis pekerjaan lbu.

Penelitian ini juga sejalan dengan penelitian yang dilakukan oleh Vongvichit, dkk (2003 ), menyatakan bahwa salah satu faktor yang mempengaruhi kepatuhan ibu hamil dalam mengkonsumsi zat besi adalah pengetahuan ibu hamil tentang anemia.

Pengetahuan merupakan domain yang sangat penting untuk terbentuknya tindakan seseorang. Pengetahuan 
diperlukan sebagai dukungan dalam menumbuhkan rasa percaya diri maupun sikap dan perilaku setiap hari, sehingga dapat dikatakan bahwa pengetahuan merupakan fakta yang mendukung tindakan seseorang (Notoadmojo, 2010). Pengetahuan merupakan salah satu faktor yang mempengaruhi perilaku kesehatan. Ibu hamil yang mengetahui dan memahami akibat anemia serta cara mencegah anemia akan mempunyai perilaku dan tindakan yang positif sehingga dapat terhindar dari dampak dan risiko anemia pada masa kehamilan. Purbadewi dan Ulvie (2013), menyatakan bahwa pengetahuan yang baik akan akan mempengaruhi perilaku kesehatan sehingga berpengaruh terhadap perilaku kesehatan.

\section{Status Gizi dengan anemia ibu hamil}

Untuk penelitianini, status gizi ibu yang diukur melalui LILA mencerminkan cadangan zat gizi dan kondisi status gizi ibu di masa pra hamil. Berdasarkan hasiluji fisher's exact, menunjukkan status gizi tidak ada hubungan bermakna dengan kejadian anemia pada lbu hamil. Hal ini menyatakan bahwa, tidak ada perbedaan ibu hamil yang Lila <23,5dengan Lila $\geq 23,5$.

Penelitian Fatimah S, dkk (2011) melaporkan bahwa ada hubungan antara status gizi (LILA) dengan kejadian anemia pada ibu hamil. Status gizi ibu yang diuku rmelalui LILA mencerminkan cadangan zat gizi dan kondisi status gizi ibu di masa pra hamil. Kekurangan gizi sebelum hamil akan berpengaruh terhadap status gizi ibu selama mengandung, yang membuat kebutuhan gizinya lebih tinggi dibandingkan ibu yang tidak kekurangan gizi, untuk memenuhi kebutuhan ibu dan janinnya. Apabila pada saat hamil, ibu mengalami kurang energy kronis (KEK) akan mengakibatkan terjadinya anemia.

Namun, hasil penelitian ini tidak sejalan dengan penelitian Fatimah $\mathrm{S}$, dkk disebabkan lbu hamil di wilayah Puskesmas Kereng Bangkirai 95\% lila $\geq$ $23,5 \mathrm{~cm}$ dan lebih banyak lbu hamil yang lila $\geq 23,5 \mathrm{~cm}(49,2 \%)$ mengalami anemia dibandingkan $\mathrm{lbu}$ dengan lila $<23,5 \mathrm{~cm}$ $(1,8 \%)$. Penelitian Alene K.A dan Dohe A.M (2014) juga menemukan bahwa lbu hamil dengan lila $\geq 23,6 \mathrm{~cm}$ dapat menurunkan risiko kejadian anemia. Hal ini disebabkan, karena lbu hamil kemungkinan kekurangan konsumsi asupan zat besi. Pada penelitian ini juga menemukan hal yang sama, Ibu hamil sebesar $80,7 \%$ mengkonsumsi zat besi $<90$ tablet selama masa kehamilan.

\section{KESIMPULAN}

Kesimpulan dari hasil penelitian ini adalah sebagai berikut:

Pengetahuan ibu hamil tentang anemia merupakan faktor risiko kejadian anemia pada ibu hamil. Sedangkan, status giziibu hamil dengan pengukuran lila tidak terdapat hubungan bermakna kejadian anemia pada ibu hamil 


\section{DAFTAR PUSTAKA}

1. Prawirohardjo, Sarwono. 2011. IImu Kebidanan. Jakarta: Yayasan Bina Pustaka Sarwono Prawirohardjo.

2. Proverawati, A. 2013. Anemia dan Anemia Kehamilan. Yogyakarta : Nuha Medika.

3. Fajrin A, Sudargo T, Waryana. 2012. Faktor Risiko Sosial Ekonomi, Asupan Zat Besi Terhadap Kejadian Anemia Pada Anak Sekolah Dasar. Gizi Indonesia 35(1)

4. Maskey M, Jha N, Poundel SI, Yadev D. 2014. Anemia in pregnancy and its associated factors: a study from Eastern Nepal. Nepal journal of epidemiology.4(4)

5. Dinkes. 2015. Profil Kesehatan Kota Palangka Raya. Palangka Raya

6. Jiji Darling B, Rajagopal K. 2014. A Study to Asses the Knowledge and Risk Factors of Anemia Among The Pregnant Women Attending Selected Health Care Facilities in Sebha, Libya. Journal of Science Obstetric \& Gynaecology. 4(1)

7. Vongvichit $P$, Isaranurung $S$, Nanthamongkolchai S, Voramongkol N. 2003. Compliance of pregnant women regarding iron supplementation in Viettiane Municipality, Lao P.D.R. Jurnal of Public Health and Development. Vol 11 (1)

8. Notoadmojo S.2010. IImu Perilaku Kesehatan. Jakarta:PT Rineka Cipta

9. Purbadewi L, Ulvie YNS. 2013. Hubungan tingkat pengetahuan tentang anemia dengn kejadian anemia pada ibu hamil. Jurnal gizi Universitas Semarang. Vol 2(1)

10. Fatimah S, Hadju V, Bahar B, Abdullah Z. 2011. Pola Konsumsi dan Kadar Hemoglobin pada lbu Hamil di Kabupaten Maros Sulawesi Selatan. Makara Kesehatan. 15(1)

11. Alene K.A, Dohe A.M. 2014. Prevalance of anemia and associated factor among pregancy women in an urban area of eastern Ethiopia. Hindawi Publishing Corporation.

12. Kementerian Kesehatan RI. 2015. Profil kesehatan Indonesia. Jakarta
13. Makhoul Z, Taren D, Duncan B, Pandey $\mathrm{P}$, Thomson C, Winzerling J, Muramoto M Shrestha. 2012. Risk Factors Associated with Anemia, Iron Deficiency Anemia in Rural Nepali Pregnant Women. Southeast Asian J Trop Med Public Health. 43(3)

14. Saifuddin AB. 2006. Buku Acuan Nasional Pelayanan Kesehatan Maternal dan Neonatal. JNPKKR. Jakarta. 